\title{
Bootstrap Causality Tests of the Relationship Between the Equity Markets of the US and Other Developed Countries: Pre- and Post-September 11
}

\author{
Abdulnasser Hatemi-J ${ }^{\mathrm{a}}$, Eduardo Roca ${ }^{\mathrm{b}}$ and Daniel Buncic ${ }^{\mathrm{c}}$
}

\begin{abstract}
a Department of Accounting, Finance and Economics, Griffith University, Nathan, Queensland, Australia 4111; Dohuk University, Kurdistan; tel: 6173875 7583; fax: 6173875 7760; email: A.Hatemi-J@griffith.edu.au.

${ }^{\mathrm{b}}$ Department of Accounting, Finance and Economics, Griffith University, Nathan, Queensland, Australia 4111; tel: 6173875 7583; fax: 6173875 7760; email: E.Roca@griffith.edu.au. (corresponding author)

c School of Economics, University of New South Wales, Sydney, Australia (d.buncic@unsw.edu.au)
\end{abstract}

\section{Abstract}

We analyse the causal relationship between the equity markets of the US and those of the UK, Japan, Germany, France, Canada and Australia based on leveraged bootstrap approach developed by Hacker and Hatemi-J (2005). This method overcomes problems of non-normalities and ARCH effects in the data. Using weekly MSCI price indices, we focus our investigation on the period 1998 to 2005 which we divided into two sub-periods to take into account the potential structural break arising from September 11. Our results show that before September 11, there was bidirectional causality between the US and Japan and between the US and Germany. In addition, there was also a unidirectional causality from the US to Canada and from the US to France. After September 11, the only causality was a unidirectional one from the US to Japan and from the UK to the US. Thus, after September 11, the US Grangercaused a fewer number of markets. This could imply that after September 11, the other markets became more efficient in responding to information transmitted from the US market.

JEL: C32, F31, G15

Keywords: Bootstrapping; Causality Test; September 11; Equity Market Linkage

Running Title: Bootstrap Causality Test of Equity Market Relationship

\section{Introduction}

The causal linkage between international financial markets is an issue that has theoretical, practical and policy importance. It has implications for international portfolio diversification, open macroeconomics in terms of the Mundell-Fleming theories, market efficiency, international financial market integration, and international financial contagion risk, among others. If markets are found to be causally linked, this may indicate inefficiency in the transmission of information, less desirability for international portfolio diversification, or increased risk of contagion. Although this issue has been investigated previously in a number of studies (see, for instance, Jeon and Von Furstenberg, 1990; Hirayana and Tsutsui, 1998; and Roca, 1999, among others), we provide the following contributions in this study.

First, we examine the interactions between the equity markets of the US and other markets, taking into account the potential structural break created by September 11. It is well-accepted that the US market drives other markets 
worldwide (see, for instance, Espitia and Santamaria, 1994). September 11 was a horrible event which disrupted trade and investment interactions between the US and other countries, and therefore it is possible that the US equity market's interactions with other equity markets may have been significantly affected too. Did September 11 change the causal linkages between the US and other markets? Considering the primary role that the US market plays worldwide, these questions are therefore important to international portfolio investors, and to economic and financial policymakers and regulators. At present, unfortunately, there is only one study (Hon and Yong, 2004), which has investigated the effect of September 11 on the linkages between markets. Our study therefore attempts to fill this knowledge gap.

Secondly, we make use of a new methodology in measuring causal effects that overcomes problems arising out of non-normalities and autoregressive conditional hetersoskedasticity (ARCH) in the data. Previous studies on stock market linkages have mainly used asymptotic approaches. However, it is known that this method leads to bias in statistical inference in small samples when non-normalities and ARCH effects are present in the data, which is often the case with financial data (Hatemi-J, 2002). In this study, we make use of a leveraged bootstrap test introduced by Hacker and Hatemi-J (2005a), which is robust to non-normalities and ARCH effects. We also utilise a new information criterion developed by Hatemi-J (2003) to determine the optimal lag of the vector autoregression (VAR) model, which performs well if the underlying data is non-stationary. In addition, we apply a new test, developed by Hacker and Hatemi-J (2005b), to determine the existence or absence of multivariate ARCH effects.

We therefore provide fresh evidence on the issue of equity market causal linkages taking into account the potential structural break created by September 11 with the use of new developments in time series econometrics that overcome problems of non-stationarity, ARCH effects and non-normalities. We focus our investigation on the US and the developed markets of the UK, Japan, Germany, France, Canada and Australia. Given the increase in uncertainty resulting from September 11, international investors will be more inclined to consider more stable markets, such as developed markets, provided these markets also offer diversification gains and/or positive net present value opportunities. Since international diversification benefits depend on the correlation between markets, the results of this study would be useful to international investors.

\section{Brief Literature Review}

There is a significant body of literature on the causal linkages between equity markets. These studies utilised different methodologies ranging from the use of simple correlations, cointegration, ARCH modelling, variance decomposition and impulse response analyses and have covered different time periods and different markets ${ }^{1}$. There is no agreement among these studies as to which market causes which, except, however, with respect to the role of the US market. These studies generally agree that the US is the most influential market worldwide (Espita and Santamaria, 1994). An example of these studies is that of Jeon and Von Furstenberg (1990), which analysed the linkages between the Tokyo, London, Frankfurt and New York stock markets using daily data in local currency over the period 1986 to 1988. Another one is that of Rogers (1994), which investigated the price interactions between the equity markets of the US, Japan, Germany, UK, Taiwan, South Korea, Thailand, Mexico and Chile based on daily price data in US dollars also

\footnotetext{
${ }^{1}$ See Roca (2000) for a summary of these studies.
} 
for the period 1986 to 1988. Gjerde and Saettem (1995) examined the price links between the stock markets of eight European countries, Japan and the US based on daily data and found the same conclusion. Hirayama and Tsutsui (1998) also found similar results in their investigation of the interactions between the equity markets of Japan, UK, US and Germany from 1974 to 1995 . Other studies which document the dominance of the US market are those of Elyasiani, Perera and Puri (1998), Chowdhury (1994), Masih and Masih (1997 and 1999), Roca (1999), among others.

These studies, however, covered only the period before September 11. At present, as far as we know, there is only study, that of Hon and Yong (2004) that examined the impact of September 11 on the links of the US market with those of others. We therefore address this gap in our study. Furthermore, most of the studies on equity market linkages have been based on asymptotic estimation procedures. ${ }^{2}$ Given that financial data is well-established to possess non-normalities and ARCH effects, it is possible that previous studies may have suffered from bias in statistical inference since it has been demonstrated in the literature that this is usually the case when such properties in the data exist (see, for example, Chunchachinda, Dandapani, Hamid and Prakash (1997) and Hatemi-J, 2002). Our study also addresses this gap in the literature. As stated earlier, we use a new methodology to determine the causal links between the equity market of the US and those of Japan, UK, Canada, and Australia, taking into account the possible impact of the structural break coming from September 11, that is robust to non-normalities and ARCH effects. We perform a causality ${ }^{3}$ test using leveraged bootstrap test based on the procedures developed by Hacker and Hatemi-J (2005a). This method is described in Section 4 of the study.

\section{Data}

We utilise weekly closing price data from the Morgan Stanley Capital International (MSCI) index for the countries of the UK, Germany, France, Australia and the U.S., Canada and Japan, denominated in US dollars, spanning from the $6^{\text {th }}$ of January 1998 to the $5^{\text {th }}$ of September 2005. The use of weekly data avoids issues relating to "day of the week" effects, commonly a problem when dealing with daily data. Weekly data also avoids problems of trading hour inconsistencies and, as Bailey and Stulz (1990) have put it, "too much trading noise” in the data in general. The year 1998 was chosen as the starting point of the estimation period. There is consensus in the literature (Roger, 2001) that most markets have started to recover from the Asian crisis at the beginning of this year.

The preference for the MSCI database arose from its ease of comparability, consistency in index calculation and avoidance of cross-listings of stock between the indices analysed. The broad based, general market indices provided by local stock exchanges are usually comprised by a different number of stocks, different firm sizes, and do not explicitly adjust for cross-listings of stock across financial markets ${ }^{4}$. Due to its consistent computation using a market

\footnotetext{
${ }^{2}$ One exception is the study by Hatemi-J and Roca (2004).

${ }^{3}$ We apply the definition of causality suggested by Granger (1969). That is we test whether one variable precedes another variable or not.

${ }^{4}$ If, for example, local equity market indices such as the FTSE100 and the All Ordinaries were utilised, the problem of the stocks of British-American Tobacco, Rio Tinto and Cable \& Wireless being cross-listed on both stock exchanges would have been encountered. Additionally, equity market indices are not computed homogeneously. The Dow Jones, for example, consists of 30 stocks not weighted by their market capitalisation, while both the FTSE100 and the All Ordinaries are capitalisation-weighted indices.
} 
capitalisation value weighted formula, and hence easy comparability, the MSCI database is highly regarded in the finance literature ${ }^{5}$.

\section{Methodology}

In this paper, as mentioned earlier, we test the causality between the equity markets of the US and those of the Japan, UK, Germany, France, Canada and Australia. We apply a Granger causality test based on bootstrapping with leveraged adjustment (Hacker and Hatemi-J, 2005a). As also mentioned previously, we make use of a new information criterion to determine the lag order in performing the causality test.

We describe in this section the procedures that we followed in implementing this methodology. Before conducting the causality test, we first analyse the time series properties of the data. We determine the order of integration of the variables by performing a unit root test. We take into account potential structural breaks occurring in the period under study since it is well-known that such a situation can result in lower power for the test. In this regard, we apply the Perron (1989) test allowing for a structural break arising from September 11. This test has better power properties because it allows for a shift in the mean value as well as a shift in the trend for the underlying variable. It can be formally expressed in terms of the following regression:

$$
z_{t}=b_{1}+b_{2} D_{t}+f_{1} t+f_{2} D_{t} t+h H_{t}+\lambda z_{t-1}+\sum_{i=1}^{m} \theta_{i} \Delta z_{t-i}+\varepsilon_{t}
$$

where:

$t=$ the time period (the linear trend term),

$D_{t}=$ a dummy variable that takes value zero for the time period before break and one for the rest of the period,

$H_{t}=$ a dummy variable that is equal to one if the time period $t$ is the first period after that of the structural break, and is zero otherwise,

$\Delta=$ the first difference operator, and

$\varepsilon_{t}=$ a white noise error term.

The null hypothesis of one unit root is $\lambda=1$, and the alternative hypothesis of stationarity is $\lambda<1$. We include sufficient lag values of $\Delta z$ in equation (1) to make sure the error term is white noise. The optimal number of lagged differences $(m)$ is determined by including more lags until the null hypothesis of independence for $\varepsilon_{t}$ is not rejected by the $\mathrm{LM}$ test at the $5 \%$ significance level. ${ }^{6}$

Then, we test the data for normalities and presence of ARCH effects. After testing for the presence of non-normalities and ARCH effects in the data as well as the order of integration of the variables, we then investigate the causal relationship between the variables. By causality, we mean causality in the Granger (1969) sense. That is, we aim to

\footnotetext{
${ }^{5}$ For a more detailed description of the index computation methodology, see the MSCI index compilation manual, available from www.msci.com/stdindex/index.html.

${ }^{6}$ We make use of LM test because Hatemi-J (2004) shows that this test is more precise compared to alternative tests.
} 
find out whether one variable precedes another variable or not. For this purpose, the following vector autoregressive model of order $p$, $\operatorname{VAR}(p)$, is utilised:

$$
y_{t}=C_{0}+C_{1} y_{t-1}+\ldots+C_{p} y_{t-p}+e_{t}
$$

Here:

$y_{t}=$ a seven dimensional vector of dependent variables,

$\mathrm{C}_{0}=\mathrm{a}$ seven-dimensional vector of intercepts,

$\mathrm{e}_{t}=\mathrm{a}$ seven-dimensional vector of error terms, and

$C_{r}=$ a $7 x 7$ matrix of parameters for $\operatorname{lag} r(r=1, \ldots, p)$.

The optimal lag order $(p)$ in the VAR model is selected by using a new information criterion introduced by Hatemi-J (2003). This information criterion has been shown to perform well especially if the variables in the VAR model are integrated. The Hatemi-J (2003) criterion is defined as the following:

$$
H J C=\ln \left(\operatorname{det} \widehat{\Omega}_{j}\right)+j\left(\frac{n^{2} \ln T+2 n^{2} \ln (\ln T)}{2 T}\right), \quad j=0, \cdots, p .
$$

Here:

$\ln =$ the natural logarithm,

$\operatorname{det} \widehat{\Omega}_{j}=$ the determinant of the estimated variance-covariance matrix of the residuals in the VAR model

$\left(e_{t}\right)$ for lag order $j$,

$n=$ the number of variables in the model, and

$T=$ the sample size (the number of observations used to estimate the VAR model).

The lag order that is minimizing equation (3) is chosen as the optimal lag order in the empirical model.

Sims, Stock and Watson (1990) have shown that standard asymptotical distributions cannot be used to test for restrictions in the VAR model if the variables are integrated. In order to circumvent this problem when testing for causality, Toda and Yamamoto (1995) proposed the use of an augmented VAR $(p+d)$ model such as the one shown below:

$$
y_{t}=C_{0}+C_{1} y_{t-1}+\ldots+C_{p} y_{t-p} \ldots+C_{p+d} y_{t-p-d}+e_{t},
$$

Note that $d$ is the integration order of the variables. Using this model, the null hypothesis of no Granger-causality can be expressed as follows:

$$
H_{0} \text { : the row } j \text {, column } k \text { element in } A_{r} \text { equals zero for } r=1, \ldots, p \text {. }
$$

It should be pointed out that the parameters for the extra lag(s), i.e. $d$, are unrestricted in testing for Granger causality. Toda and Yamamoto (1995) demonstrated analytically that these unrestricted parameters ensure that the asymptotical distribution theory can be applied if the residuals are normally distributed. Assuming that the initial values are given, we define the following denotations in order to represent the modified Wald test statistic in a compact way:

$$
\begin{aligned}
& Y:=\left(y_{1}, \cdots, y_{T}\right) \quad(n \times T) \text { matrix, } \\
& D:=\left(C_{0}, C_{1}, \cdots, C_{p}, \cdots, C_{p+d}\right) \quad(n \times(1+n(p+d))) \text { matrix, }
\end{aligned}
$$




$$
\begin{aligned}
& Z_{t}:=\left[\begin{array}{c}
1 \\
y_{t} \\
y_{t-1} \\
\vdots \\
y_{t-p-d+1}
\end{array}\right]((1+n(p+d)) \times 1) \text { matrix, for } t=1, \ldots, T \\
& Z:=\left(Z_{0}, \cdots, Z_{T-1}\right)((1+n(p+d)) \times T) \text { matrix, and } \\
& \delta:=\left(e_{1}, \cdots, e_{T}\right)(n \times T) \text { matrix. }
\end{aligned}
$$

Via this notation, the estimated $\operatorname{VAR}(p+d)$ model is written compactly as:

$$
Y=D Z+\delta
$$

The modified Wald (MWALD) test statistic, suggested by Toda and Yamamoto (1995), for testing the null hypothesis of non-Granger causality is defined as

$$
M W A L D=(Q \hat{\beta})^{\prime}\left[Q\left(\left(Z^{\prime} Z\right)^{-1} \otimes \Omega_{U}\right) Q^{\prime}\right]^{-1}(Q \hat{\beta}) \sim \chi_{p}^{2} .
$$

Here:

$\otimes=$ element by all element matrix multiplication operator (the Kronecker product).

$Q=$ a $p \times n(1+n(p+d))$ indicator matrix used to identify restrictions implied by the null hypothesis. Each of the $p$ rows of $Q$ is associated with the restriction to zero of one parameter in $\beta$. The elements in each row of $Q$ acquire the value of one if the related parameter in $\beta$ is zero under the null hypothesis, and they get the value of zero if there is no such restriction under the null.

$\Omega_{U}=$ the estimated variance-covariance matrix of residuals in equation (6) when the restrictions implied by the null hypothesis of non-Granger causality is not imposed.

$\hat{\beta}=\operatorname{vec}(\hat{D})$, where vec signifies the column-stacking operator.

For the MWALD test statistic, the total degrees of freedom is equal to the number of restrictions to be tested which in this particular case is $p$. Asymptotically, it follows a $\chi^{2}$ distribution provided the error terms are normally distributed. However, when the error terms are non-normal and autoregressive conditional heteroscedasticity (ARCH) exists, the MWALD statistic tends to overreject the null hypothesis, as shown by Hacker and Hatemi-J (2005a) through Monte Carlo simulations. To overcome this problem, the said authors recommend a test based on leveraged bootstrap simulations. The bootstrap procedure estimates the distribution of a test statistic based on resampling the underlying data. The bootstrap-derived distribution provides more precise critical values and thus, leads to less bias in statistical inference.

To perform the bootstrap simulations, we first estimate regression (6) with the restriction implied by the null hypothesis of no Granger causality imposed. For each bootstrap simulation we generate the simulated data, $Y *$, based on the coefficient estimates from this regression, $\hat{D}$; the original $Z$ data; and $\delta^{*}$ (the bootstrapped residuals). That is:

$$
Y^{*}=\hat{D} Z+\delta^{*}
$$


Note that the bootstrap residuals are based on $T$ random draws with replacement from the regression's modified residuals, each with equal probability of $1 / T$. The mean of the resulting set of drawn modified residuals is subtracted from each of the modified residuals in that set. This adjustment is done to make sure that the mean value of the bootstrapped residuals is zero. The modified residuals are the regression's raw residuals modified to have constant variance, through the use of leverages. ${ }^{7}$ It should be mentioned that $\hat{D}$ is the estimated value of the parameters in equation (6). That is:

$$
\hat{D}=Y Z^{\prime}\left(Z Z^{\prime}\right)^{-1}
$$

We generate the distribution for the MWALD test statistic by running the bootstrap simulation 10,000 times and calculating the MWALD test statistic for each run. We then find the $(\alpha)$ th upper quantile of the distribution of bootstrapped MWALD statistics and attain the $\alpha$-level "bootstrap critical values" $\left(c_{\alpha}^{*}\right)$ pertaining to $1 \%, 5 \%$ and $10 \%$ significance levels. Afterwards, we calculate the MWALD statistic using the original data (not the bootstrapped simulated data). We reject the null hypothesis of no causality in the Granger sense at the $\alpha$ level of significance if the actual MWALD is greater than $c_{\alpha}^{*}$. The simulations are conducted using a program procedure written by Hacker and Hatemi-J (2005a). ${ }^{8}$

\section{Empirical Results}

We perform the Perron (1989) unit root test before conducting the causality test. The estimation results from the unit root test on the data are reported in Table 1. For the null hypotheses of I(1), i. e. integration of the first order, the estimated test statistics, in absolute terms, are found to be less than the critical values at the conventional significance levels. Hence, the null hypothesis that each variable is I(1) cannot be rejected. We then investigate whether each variable becomes stationary after taking the first difference - that is, we test the null hypothesis that each variable is I(2). It can be seen from the results shown in Table 1 that this null hypothesis is rejected at the one percent significance level for each variable. Hence, we can conclude that each variable contains one unit root. This implies that we have to pay attention to the integration properties of the data in order to avoid spurious and false inference.

\section{Insert here Table 1}

As stated in Section 4, prior to conducting the causality test, we also examine other properties of the data. We test for the existence of autoregressive conditional hetersoskedasticity (ARCH) by using the test developed by Hacker and Hatemi-J (2005b). The results are presented in Table 2. As is evident from these results, the null hypothesis of no multivariate ARCH effects can be strongly rejected in each period. We test also for multivariate normality in the data using the Doornik and Hansen (1994) test. The results for this test, presented in the last column in Table 2, show that the assumption of normality can be rejected at any conventional significance level. Therefore, in order to obtain more

\footnotetext{
${ }^{7}$ For more details on leverage adjustment, see Davison, and Hinkley (1999) and Hacker and Hatemi-J (2005a). The latter authors introduce this adjustment for multivariate equation cases.

${ }^{8}$ This program procedure written in Gauss to conduct leveraged bootstrap simulations as introduced by Hacker and Hatemi-J (2005a) is available on request from the authors.
} 
accurate results under the prevailing circumstances, it is essential to make use of the Hacker and Hatemi-J causality test based on the bootstrap with leveraged adjustments. This is because asymptotic methods would not perform well if the assumptions of normality and no ARCH effects are not fulfilled.

\section{Insert here Table 2}

The results of the causality test between the different markets are presented in Table 3. It can be seen that during the period before September 11, there was bi-directional causality between the US and Germany as well as between the US and Japan. In addition, there was also a uni-directional causality from the US to France and from the US to Canada. Thus, during this period, the US and Germany significantly affected each other. The same was true for the US and Japan. The US influenced France and Canada but the opposite was not true. Thus, during this period, the US Granger-caused most of the other markets. This could imply that other markets were not efficient in processing information generated by the US market.

\section{Insert here Table 3}

After September 11, however, there were significant changes in the causal relationship between the US and the other developed markets. There was only a uni-directional causality from the US to Japan and from the UK to the US. Thus, the US continued to Granger-cause Japan but Japan no longer affected the US. The UK also significantly affected the US. The US ceased to be causally linked to Germany and France. Thus, there were less causal linkages between the US and the other markets. This could indicate that the other markets became more efficient in responding to information spill-overs from the US market but the US became less efficient in digesting information from the UK market.

\section{Conclusion}

We re-examine the issue of equity market causal linkages with the use of a new methodology based on procedures developed by Hacker and Hatemi-J (2005). We also applied a new method in determining the optimal lag for the VAR model, introduced by Hatemi-J (2003) that is also robust to non-stationarity in the data. In addition, we also utilised a new method in testing for the existence or absence of ARCH effects in the data based on the procedure introduced by Hacker and Hatemi-J (2005b).

We focus on the causal linkage between the US, on one hand, and Germany, France, Japan, Canada and Australia, on the other hand, during the period before and after September 11. We found that before September 11, the US had bidirectional causalities with Japan and Germany. The US also significantly affected Canada and France but not viceversa. These results could imply that Japan, Germany, France and Canada were not efficient in responding to information generated by the US market. After September 11, the US only uni-directionally caused Japan and the UK also significantly influenced the US. Thus, after September 11, the US became less causally linked to other markets. This can indicate that other markets such as Canada, France and Germany became more efficient in absorbing information from the US market. The US, however, also became less efficient in responding to events from the UK. 


\section{References}

Bailey, W. and R. Stulz (1990). "Benefits of International Diversification: The Case of Pacific Basin Stock Markets". Journal of Portfolio Management, Summer, 57-61.

Chowdhury A. R. (1994): "Stock Market Interdependencies: Evidence from the Asian NIEs." Journal of Macroeconomics 16, 4, 629-651.

Chunchachinda, P.; Dandapani, K.; Hamid, S. and Prakash, A.J. (1997): "Portfolio Selection and Skewness: Evidence from International Stock Markets”, Journal of Banking and Finance, 21, 143-167.

Davison, A. C., and Hinkley, D.V. (1999) Bootstrap Methods and Their Application. Cambridge University Press. Cambridge, UK.

Doornik, J.A., and Hansen, H. (1994). An Omnibus Test For Univariate And Multivariate Normality. Working paper, Nuffield College, Oxford University, Oxford, UK.

Elyasiani E., Perera P. and Puri T. N. (1998): "Interdependence and Dynamic Linkages between Stock Markets of Sri Lanka and its Trading Partners." Journal of Multinational Financial Management, 8, 1, 89-101.

Espitia, M. and Santamaria, R. (1994). "International Diversification Among the Capital Markets of the EEC", Applied Financial Economics, 4, 1-10.

Gjerde O. and Sættem F. (1995): "Linkages among European and World Stock Markets." European Journal of Finance 1, 1, 165-179.

Granger, C. W. J. (1969). "Investigating Causal Relations by Econometric models and Cross Spectral Methods". Econometrica, 37, 424-438.

Hacker R. S. and Hatemi-J, A. (2005a) “Tests for Causality Between Integrated Variables Based on Asymptotic and Bootstrap Distributions: Theory and Application”. Applied Economics, forthcoming.

Hacker R. S. and Hatemi-J, A. (2005b) A Test for Multivariate ARCH Effects. Applied Economics Letters, 12, 7, 411417.

Hatemi-J, A. (2002) "Money Supply and the Informational Efficiency of the Stock Market in Korea: Evidence from an Alternative Methodology ”. Journal of Economic Integration, 17, 3, 517-526.

Hatemi-J, A. (2004) "Multivariate Tests for Autocorrelation in Stable and Unstable VAR Models". Economic Modelling, 21, 4, 661-683.

Hatemi-J, A., (2003) “A New Method to Choose Optimal Lag Order in Stable and Unstable VAR Models. Applied Economics Letters, 10, 3, 135-137.

Hatemi-J, A. and Roca E. (2004) “An Examination of the Equity Market Price Linkages Between Australia and the European Union Using Leveraged Bootstrap Method”. European Journal of Finance, 10, 6, 475-488.

Hirayama K. and Tsutsui Y. (1998): "Threshold Effect in International Linkage of Stock Prices." Japan and the World Economy 10, 4, 441-453.

Hon, M.T. and Yong, S., 2004, “Contagion in Financial Markets after September 11: Myth or Reality?” Journal of Financial Research 27, 1, 95-114.

Jeon, B.N. and Von Furstenberg, G.W. (1990). "Growing International Co-movement in Stock Price Indexes", Quarterly Review of Economics and Business, 30, 3, 15-30.

Masih A. M. M. and Masih R. (1997): "A Comparative Analysis of the Propagation of Stock Market Fluctuations in Alternative Models of Dynamic Causal Linkages." Applied Financial Economics 7, 1, 59-74. 
Masih A. M. M. and Masih R. (1999): "Are Asian Stock Market Fluctuations due mainly to Intra-Regional Contagion Effects? Evidence Based on Asian Emerging Stock Markets." Pacific Basin Finance Journal 7, 3-4, 251-282.

Perron, P. (1989). “The Great Crash, the Oil Price Shock and the Unit Root Hypothesis”. Econometrica 57, 13611401.

Roca, E.D. (1999). "Short-Term and Long-Term Price Linkages Between the Equity Markets of Australia and Its Major Trading Partners”, Applied Financial Economics, 9, 5, 501-511.

Roca, E.D. (2000). Price Interdependence Among Equity Markets in the Asia-Pacific Region: Focus on Australia and ASEAN. Aldershot, UK: Ashgate Publishing Limited.

Roger, S. (2001). “The Asian Crisis Four Years Ago”, Finance and Development, March 1-2.

Rogers J. H. (1994): "Entry Barriers and Price Movements between Major and Emerging Stock Markets." Journal of Macroeconomics 16, 2, 221-241.

Sims, C. A., Stock, J. H., Watson. M. W. (1990). "Inference in Linear Time Series Models with Some Unit Roots”. Econometrica, 58, 133-44.

Toda, H. Y., Yamamoto, T. (1995). ”Statistical Inference in Vector Autoregressions with Possibly Integrated Processes”. Journal of Econometrics, 66, 225-250. 
Table 1

Test for Unit Roots Using the Perron Test

\begin{tabular}{||c|c|c|c||}
\hline & $\mathrm{H}_{0}: \mathrm{I}(1), \mathrm{H}_{1}: \mathrm{I}(0)$ & TEST VALUE & $\mathrm{H}_{0}: \mathrm{I}(2), \mathrm{H}_{1}: \mathrm{I}(1)$ \\
\hline $\mathrm{SP}_{\mathrm{US}}$ & $-1.7(4)$ & $\mathrm{SP}_{\mathrm{US}}$ & $-10.9(3)$ \\
\hline $\mathrm{SP}_{\mathrm{JAPAN}}$ & $-1.5(0)$ & $\mathrm{SP}_{\mathrm{JAPAN}}$ & $-24.0(0)$ \\
\hline $\mathrm{SP}_{\mathrm{UK}}$ & $-2.8(0)$ & $\mathrm{SP}_{\mathrm{UK}}$ & $-20.9(0)$ \\
\hline $\mathrm{SP}_{\mathrm{GERMANY}}$ & $-1.1(20)$ & $\mathrm{SP}_{\mathrm{GERMANY}}$ & $-6.0(19)$ \\
\hline $\mathrm{SP}_{\mathrm{FRANCE}}$ & $-1.1(8)$ & $\mathrm{SP}_{\text {FRANCE }}$ & $-7.5(7)$ \\
\hline $\mathrm{SP}_{\mathrm{CANADA}}$ & $-1.5(0)$ & $\mathrm{SP}_{\mathrm{CANADA}}$ & $-22.0(0)$ \\
\hline $\mathrm{SP}_{\text {AUSTRALIA }}$ & $-2.8(0)$ & $\mathrm{SP}_{\text {AUSTRALIA }}$ & $-20.4(0)$ \\
\hline
\end{tabular}

Notes:

(a) The critical value is $-4.90,-4.24$ and -3.96 at the $1 \%, 5 \%$ and $10 \%$ significance level, respectively.

(b) The notation $* * *$ implies significance at the one percent significance level.

(c) The numbers in the parentheses indicate the number of lags required to remove potential autocorrelation in the Perron regression (equation 1) at the $5 \%$ significance level using the LM test.

Table 2

Multivariate Diagnostic Tests

\begin{tabular}{|l|c|c|}
\hline \multicolumn{1}{|c|}{ Statistic } & Period 1 & Period 2 \\
\hline Multivariate ARCH & 0.0000 & 0.0000 \\
\hline Multivariate Normality & 0.0001 & 0.0002 \\
\hline
\end{tabular}

The null hypothesis of no multivariate ARCH effects is tested by using a new test introduced by Hacker and Hatemi-J (2005b). The null hypothesis of multivariate normally is tested by applying Doornik and Hansen (1994) test. The p-values are presented here.

Table 3

Causality Tests Based on Hacker and Hatemi-J Bootstrap Causality Test (January 1998 to September 10, 2001)

\begin{tabular}{|c|c|c|c|c|}
\hline $\begin{array}{c}\text { THE NULL } \\
\text { HYPOTHESIS }\end{array}$ & $\begin{array}{c}\text { THE ESTIMATED } \\
\text { TEST VALUE } \\
\text { (MWALD) }\end{array}$ & $\begin{array}{c}1 \% \\
\text { BOOTSTRAP } \\
\text { CRITICAL } \\
\text { VALUE }\end{array}$ & $\begin{array}{c}5 \% \\
\text { BOOTSTRAP } \\
\text { CRITICAL } \\
\text { VALUE }\end{array}$ & $\begin{array}{c}\text { 10\% BOOTSTRAP } \\
\text { CRITICAL } \\
\text { VALUE }\end{array}$ \\
\hline $\mathrm{SP}_{\mathrm{US}} \neq>\mathrm{SP}_{\text {JAPAN }}$ & $5.7 * *$ & 10.6 & 5.1 & 4.4 \\
\hline $\mathrm{SP}_{\mathrm{JAPAN}} \neq>\mathrm{SP}_{\mathrm{US}}$ & $5.4^{*}$ & 12.6 & 5.9 & 4.5 \\
\hline $\mathrm{SP}_{\mathrm{US}} \not>\mathrm{SP}_{\mathrm{UK}}$ & 3.06 & 8.5 & 5.9 & 4.0 \\
\hline $\mathrm{SP}_{\mathrm{UK}} \neq>\mathrm{SP}_{\mathrm{US}}$ & 1.4 & 12.5 & 5.8 & 4.7 \\
\hline $\mathrm{SP}_{\mathrm{US}} \neq>\mathrm{SP}_{\mathrm{GERMANY}}$ & $5.8^{*}$ & 9.2 & 6.0 & 4.8 \\
\hline $\mathrm{SP}_{\text {GERMANY }} \not>\mathrm{SP}_{\mathrm{US}}$ & $10.2^{* * *}$ & 8.8 & 6.0 & 5.3 \\
\hline $\mathrm{SP}_{\mathrm{US}} \neq>\mathrm{SP}_{\mathrm{FRANCE}}$ & $15.3^{* * *}$ & 10.1 & 7.0 & 4.5 \\
\hline $\mathrm{SP}_{\text {FRANCE }} \neq>\mathrm{SP}_{\mathrm{US}}$ & 1.3 & 7.1 & 5.9 & 4.2 \\
\hline $\mathrm{SP}_{\mathrm{US}} \neq>\mathrm{SP}_{\mathrm{CANADA}}$ & $6.4^{*}$ & 15.1 & 7.2 & 5.0 \\
\hline $\mathrm{SP}_{\mathrm{CANADA}} \neq>\mathrm{SP}_{\mathrm{US}}$ & 4.8 & 9.4 & 5.7 & 4.9 \\
\hline $\mathrm{SP}_{\mathrm{US}} \neq>\mathrm{SP}_{\text {AUSTRALIA }}$ & 1.3 & 10.9 & 7.2 & 5.9 \\
\hline $\mathrm{SP}_{\text {AUSTRALIA }} \neq>\mathrm{SP}_{\text {US }}$ & 3.3 & 8.6 & 6.3 & 4.8 \\
\hline
\end{tabular}

Notes:

(a) The notation $\neq>$ implies non-Granger causality.

(b) MWALD represents the modified Wald test statistic as described in equation (7).

(c) The lag order of the VAR model, $p$, was set to five. Also the augmentation lag, $d$, was set to one since each variable contains one unit root.

(d) * signifies that the null hypothesis is rejected at the ten percent significance level

** signifies that the null hypothesis is rejected at the five percent significance level

*** signifies that the null hypothesis is rejected at the one percent significance level. 
Table 4

Causality Tests Based on Hacker and Hatemi-J Bootstrap Causality Test

(September 11, 2001 to September 2005)

\begin{tabular}{|c|c|c|c|c|}
\hline $\begin{array}{l}\text { THE NULL } \\
\text { HYPOTHESIS }\end{array}$ & $\begin{array}{c}\text { THE } \\
\text { ESTIMATED } \\
\text { TEST VALUE } \\
\text { (MWALD) } \\
\end{array}$ & $\begin{array}{c}1 \% \\
\text { BOOTSTRAP } \\
\text { CRITICAL } \\
\text { VALUE } \\
\end{array}$ & $\begin{array}{c}5 \% \\
\text { BOOTSTRAP } \\
\text { CRITICAL } \\
\text { VALUE } \\
\end{array}$ & $\begin{array}{c}\text { 10\% BOOTSTRAP } \\
\text { CRITICAL } \\
\text { VALUE }\end{array}$ \\
\hline $\mathrm{SP}_{\mathrm{US}} \neq>\mathrm{SP}_{\text {JAPAN }}$ & $5.9 *$ & 11.2 & 7.0 & 5.4 \\
\hline $\mathrm{SP}_{\text {JAPAN }} \neq>\mathrm{SP}_{\mathrm{US}}$ & 1.5 & 9.9 & 7.0 & 5.2 \\
\hline $\mathrm{SP}_{\mathrm{US}} \not>\mathrm{SP}_{\mathrm{UK}}$ & 2.6 & 7.8 & 5.4 & 4.7 \\
\hline $\mathrm{SP}_{\mathrm{UK}} \neq>\mathrm{SP}_{\mathrm{US}}$ & $14.3^{* * *}$ & 9.5 & 6.9 & 5.3 \\
\hline $\mathrm{SP}_{\mathrm{US}} \neq>\mathrm{SP}_{\mathrm{GERMANY}}$ & 4.0 & 9.2 & 5.1 & 4.2 \\
\hline $\mathrm{SP}_{\text {GERMANY }} \neq>\mathrm{SP}_{\text {US }}$ & 4.1 & 9.1 & 5.7 & 4.7 \\
\hline $\mathrm{SP}_{\mathrm{US}} \neq>\mathrm{SP}_{\mathrm{FRANCE}}$ & 0.8 & 9.2 & 6.8 & 4.6 \\
\hline $\mathrm{SP}_{\text {FRANCE }} \neq>\mathrm{SP}_{\mathrm{US}}$ & 2.8 & 8.2 & 5.4 & 4.1 \\
\hline $\mathrm{SP}_{\mathrm{US}} \neq>\mathrm{SP}_{\mathrm{CANADA}}$ & 2.5 & 9.8 & 6.4 & 4.7 \\
\hline $\mathrm{SP}_{\text {CANADA }} \neq>\mathrm{SP}_{\mathrm{US}}$ & 0.0 & 13.5 & 6.9 & 5.0 \\
\hline $\mathrm{SP}_{\mathrm{US}} \neq>\mathrm{SP}_{\text {AUSTRALIA }}$ & 2.7 & 4.5 & 4.7 & 4.0 \\
\hline $\mathrm{SP}_{\text {AUSTRALIA }} \neq>\mathrm{SP}_{\text {US }}$ & 2.0 & 9.9 & 5.3 & 3.7 \\
\hline
\end{tabular}

Notes:

(e) The notation $\neq>$ implies non-Granger causality.

(f) MWALD represents the modified Wald test statistic as described in equation (7).

(g) The lag order of the VAR model, $p$, was set to five. Also the augmentation lag, $d$, was set to one since each variable contains one unit root.

(h) $* * *$ signifies that the null hypothesis is rejected at the one percent significance level.

* signifies that the null hypothesis is rejected at the ten percent significance level 